\title{
Model for Predicting the Machinability of Continuously Cast and Subsequently Rolled Steel Using the Artificial Neural Network
}

\author{
Miha Kovačič゙, Shpetim Salihu, Uroš Župerl
}

\begin{abstract}
The paper presents a model for predicting the machinability of steels using the method of artificial neural networks. The model includes all indicators from the entire steel production process that best predict the machinability of continuously cast steel. Data for model development were obtained from two years of serial production of 26 steel grades from 255 batches and include seven parameters from secondary metallurgy, four parameters from the casting process, and the content of ten chemical elements. The machinability was determined based on ISO 3685, which defines the machinability of a batch as the cutting speed with a cutting tool life of 15 minutes. An artificial neural network is used to predict this cutting speed. Based on the modelling results, the steel production process was optimised. Over a 5-month period, an additional 39 batches of $20 \mathrm{MnV} 6$ steel were produced to verify the developed model.
\end{abstract}

Keywords: calcium treated steel; continuous casting; machinability; modelling; neural network; steelmaking

\section{INTRODUCTION}

Research in the steelmaking industry is usually focused on analysing the individual characteristics of one type of material or one type of steel and often does not include the possibility of direct practical implementation of the results in mass production of steel. Thus, it is not possible to find in the literature practical instructions for changing the technology of the steel production process.

This article deals with the analysis of the influences of material properties on machinability. In the literature, machinability is defined as the material's ability to be machined at the lowest possible machining cost [1]. Improved machinability of the material leads to increased tool life, increased cutting performance, lower energy consumption and optimal surface quality. Machinability is influenced by the properties of the material and machining. For example, the machinability of carbon and alloyed steel is affected by the chemical composition; size, morphology, distribution and type of inclusions; macrostructure; microstructure; machining parameters and cutting tool.

The effects of individual chemical elements on the machinability of steels have been well known for decades [14]. Silicon, sulfur, phosphorus, lead, tellurium, bismuth, and antimony positively affect machinability. These elements are added to form inclusions with the correct chemical composition, morphology, size, and distribution. The effects of individual alloying elements on the steel matrix and consequently on the material's mechanical properties are not known [1, 4-5].

Researches dealing with the impacts of inclusions can be divided into two groups. The first group analyses the addition of inclusions to form additions, while the second group deals with the effects of chemical composition, morphology, size and distribution of inclusions [6-8].

In this study, the effects of the entire steelmaking process on the machinability of 25 different calcium treated steel grades were analysed. Chemical composition, deoxidising agents and casting parameters were included in predicting the machinability of continuously cast and later rolled material.

The first part of the paper presents the problem of achieving steel machinability and collecting data for predicting machinability. The process for determining workability according to ISO $3685: 1993$ [9] is briefly presented. The following section presents a model for predicting machinability based on artificial neural networks. Then, the results of optimisation of the 20MnV6 steel production process using predictive analytics are given. The last chapter provides conclusions and plans for future work.

\section{STEEL MAKING PROCESS, MATERIALS AND METHODOLOGY}

The steel plant in Štore is one of the largest European producer of flat spring steels. The steel plant produces more than 40 grades of calcium-treated steel with various chemical compositions, representing up to $15 \%$ of total production. Steel grade 20MnV6 is the most produced steel in Štore steel.

Spring steel production is carried out by melting scrap steel in an electric arc furnace, tapping, ladle treatment and continuous casting of the billets. The ladle treatment process is also known as secondary metallurgy. The cooled billets are then reheated and rolled in a rolling hall. The billets are rolled into a bar with a round cross-section and a diameter of $90 \mathrm{~mm}$ The rolled bars are then further straightened, inspected, cut to lengths $(1.2 \mathrm{~m})$, drilled, peeled, and chamfered in a cold finishing hall. The rod is now ready for the machinability test according to ISO $3685: 1993$. This standard defines the implementation of tool life testing with single-current turning tools [9]. ISO 3685:1993 stipulates that a constant cutting speed must be maintained during the turning process when reducing the workpiece diameter. The rods are turned to a diameter of $35 \mathrm{~mm}$ with a cutting depth of $4 \mathrm{~mm}$ and a feed rate of $0.24 \mathrm{~mm} / \mathrm{rev}$. Tool wear measurements at specified cutting speeds are made at appropriate intervals and recorded in time-tool wear diagrams with at least five experimental points for each wear curve (Fig. 1). The following cutting 
tool wear criteria for sintered carbide cutting inserts are used in this research (Fig. 2): The maximum flank wear VBB max is equal to or greater than $0.5 \mathrm{~mm}$, the average flank wear is equal to or greater than $0.3 \mathrm{~mm}$, crater wear is equal to or greater than $0.17 \mathrm{~mm}$, the front distance of the crater is reduced to the value of $K F=0.03 \mathrm{~mm}$ and cutting-edge failure.

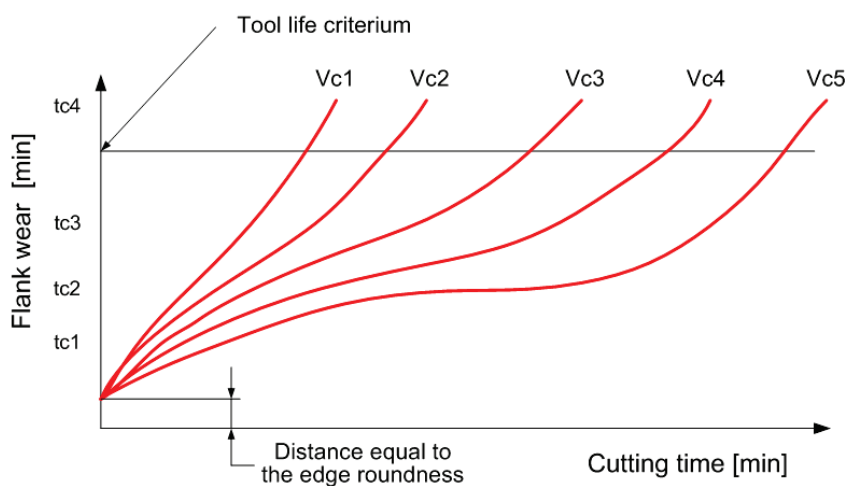

Figure 1 Construction of flank wear curves with respect to machining time for different cutting speeds

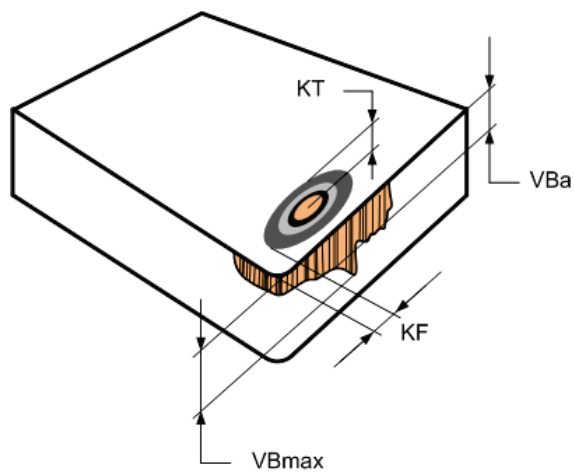

Figure 2 Maximum and average flank wear (VBmax, $V B)$, crater wear $(K T)$ and the crater front distance $(K F)$.

Tool wear was determined using a profile projector, stopwatch, a microscope and a dial. The tool wear measurements at different cutting speeds were then presented in cutting tool life diagrams concerning cutting speeds (Fig. 3 ). Under certain conditions, tool life can be expressed in minutes of tool life at only one selected cutting speed.

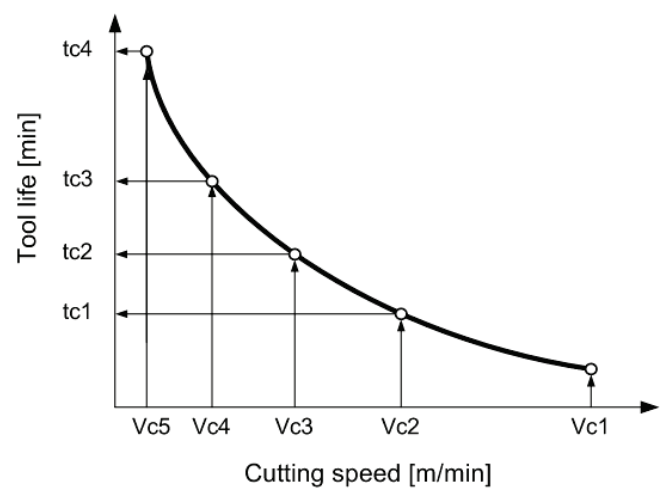

Figure 3 Graph of tool life versus cutting speed
In subsequent machinability tests of the same type of steel, the test always begins with machining at a previously obtained cutting speed, where the tool wears out in 15 minutes. During the machinability test, the time in which the tool wears out is measured. Time in minutes represents the tool life, based on which the actual cutting speed is determined from the diagram (Fig. 4). Then, the calculated actual cutting speed is compared to the previously obtained cutting speed at which the tool wears out in 15 minutes (Fig 4). The machinability of the test material is adequate if the actual speed is greater than or equal to the cutting speed at which the tool wears within 15 minutes.

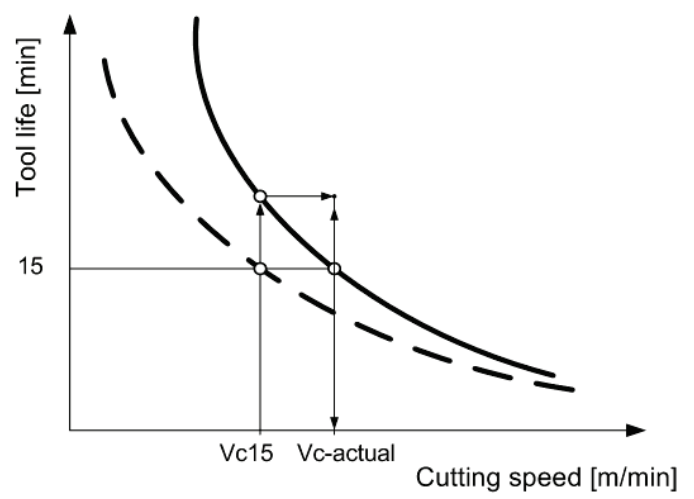

Figure 4 Determination of actual cutting speed for tested material

Therefore, the cutting speed at which the tool has a tool life of 15 minutes was chosen as the machining criterion (Fig. 4). From 2018 to March 2020, 255 batches with 26 different calcium treated steel grades were cast in succession. During the continuous casting process, the following parameters were monitored:

- Calcium carbide cored wire length [m] is used to modify aluminum silicate inclusions (Ladle treatment).

- Ladle treatment time [min] includes raffination, argon stirring, alloying, heating, slag forming, taking of samples and technological delays.

- Calcium silicon cored wire length $[\mathrm{m}]$ is used to modify aluminium silicate inclusions.

- Alloying elements added to the melt via automatic feeders: Ferrochromium with low carbon content $(\mathrm{kg})$, Ferrochromium with high carbon content (kg), Ferromanganese (kg), Ferromolybdenum (kg), Ferrosilicon (kg), Ferrovanadium (kg), Nickel (kg), Sulfur cored wire $[\mathrm{m}]$ and Silicon manganese $(\mathrm{kg})$.

Parameters of the continuous casting process:

- The average temperature of casting $\left({ }^{\circ} \mathrm{C}\right)$

- The difference between the inlet and outlet temperature of the coolant in the process of primary cooling $\left({ }^{\circ} \mathrm{C}\right)$.

- Cooling water pressure directly below the mold and in the second secondary cooling zone (bar).

- Chemical composition (\%) affects the microstructure and mechanical properties. The chemical composition includes carbon, silicon, manganese, sulfur, chromium, molybdenum, nickel, aluminium, vanadium and calcium. 
- The cutting speed at which the tool wears out within 15 minutes for individual batch $(\mathrm{m} / \mathrm{min})$.

Tab. 1 shows the ranges of the monitored parameters.

Table 1 Monitored parameters with limit values

\begin{tabular}{|c|c|c|c|c|}
\hline Label & Parameter & Unit & Min. & Max. \\
\hline DELTATEMP & Average difference between input and output water temperature for each mold & ${ }^{\circ} \mathrm{C}$ & 4.66 & 8.78 \\
\hline $\mathrm{CAC} 2$ & Calcium carbide cored wire & $\mathrm{m}$ & 0 & 215 \\
\hline CASI & Calcium silicon cored wire & $\mathrm{m}$ & 0 & 340 \\
\hline $\mathrm{C}$ & Carbon content & $\%$ & 0.08 & 0.55 \\
\hline $\mathrm{CR}$ & Chromium content & $\%$ & 0.06 & 2 \\
\hline FEMN & Ferromanganese & $\mathrm{kg}$ & 0 & 1004 \\
\hline FEMO & Ferromolybdenum & $\mathrm{kg}$ & 0 & 274 \\
\hline FESI & Ferrosilicon & $\mathrm{kg}$ & 0 & 337 \\
\hline FEV & Ferrovanadium & $\mathrm{kg}$ & 0 & 106 \\
\hline TIMEL & Ladle treatment time & $\min$ & 24 & 100 \\
\hline MN & Manganese content & $\%$ & 0.34 & 1.59 \\
\hline $\mathrm{S}$ & Sulfur content & $\%$ & 0.013 & 0.059 \\
\hline SM & Sulfur cored wire & $\mathrm{m}$ & 0 & 110 \\
\hline P1 & The average cooling water pressure in the first zone of secondary cooling & bar & 2.61 & 6.68 \\
\hline P2 & The average cooling water pressure in the second zone of secondary cooling & bar & 1.53 & 4.93 \\
\hline Vc15 & The cutting speed where the tool wears out within 15 minutes for individual batch & $\mathrm{m} / \mathrm{min}$ & 210 & 450 \\
\hline $\mathrm{V}$ & Vanadium content & $\%$ & 0 & 0.14 \\
\hline
\end{tabular}

\section{MODEL FOR PREDICTING THE CUTTING FORCE AT WHICH THE CUTTING TOOL LIFE IS 15 MINUTES}

This research aims to design and test the methodology for predicting the cutting speed Vc15, which serves as a criterion for the machinability of all calcium-treated steel grades produced in Štore steel plant. Furthermore, the chapter presents in detail the adaptation of the artificial neural network (ANN) architecture to the problem of cutting speed prediction.

The average deviation between the predicted and experimental data is selected for the Fitness function, which is calculated according to the equation:

$$
\Delta=\frac{\sum_{i=1}^{n}\left|Q_{i}-Q_{i}^{\prime}\right|}{n},
$$

where $n$ is the size of the acquisition data and $Q_{i}^{\prime}$ and $Q_{i}$ are the actual and the predicted actual cutting speed. The popular four-layer feedforward neural network architecture perfectly aligned with the back propagation learning algorithm was used to perform Vc15 cutting speed modeling. The designed ANN has 26 input neurons for modelling (see Fig. 5). The optimal number of hidden layers, the number of neurons in each hidden layer, the training parameters, and the optimal type of activation function were determined by systematically varying the parameters in the simulations. The optimal ANN architecture contains 15, 12, 6, and 10 neurons in each hidden layer. The output from the ANN is the cutting speed; therefore, only one output neuron is required. Signals are transmitted between neurons, which are transformed on neurons by the ArcTangent activation function. Fig. 5 shows a detailed architecture of the developed neural model for cutting speed predictions.

Four steps are required to develop a neural model of cutting speed. In Step 1, data sets for learning and testing were presented to ANN. A total of 2800 scaled data points were used as inputs and outputs for ANN training. In addition, $30 \%$ of this data was used to test the ANN to verify the accuracy of the predicted values. In step 2, the ANN topology and learning parameters were defined. The number of hidden layers, the number of neurons, the momentum rate $(\beta)$, the learning rate $(\alpha)$, the total network error and the maximum number of training iterations were determined. To determine the effects of individual parameters on ANN performances, 72 different network topologies were trained, tested, and analysed. In addition, neural networks performances were evaluated by fitness function and number of training iterations. Based on the simulation results, it is determined that the Optimal number of neurons in the hidden layers is 24 , the learning rate $\alpha$ should be less than 0.2 and the momentum rate $\beta$ should be between 0.008 and 0.01 . In step 3, the network training and testing process is performed. During training, ANN adjusts its internal structure by adjusting the weights on the synapses to get the correct output results according to the input features.

2800 sets of experimental data are used to conduct 1075 iterations of training. Artificial neural network training stops when the prediction error reaches the lower defined limit within 1075 iterations of training. It was found that the test 
error for $30 \%$ of all data points converged to $2.9 \%$. Fig. 6 shows the scatter diagram of the predicted values and experimentally determined values of the $\mathrm{Vc} 15$ for testing data.

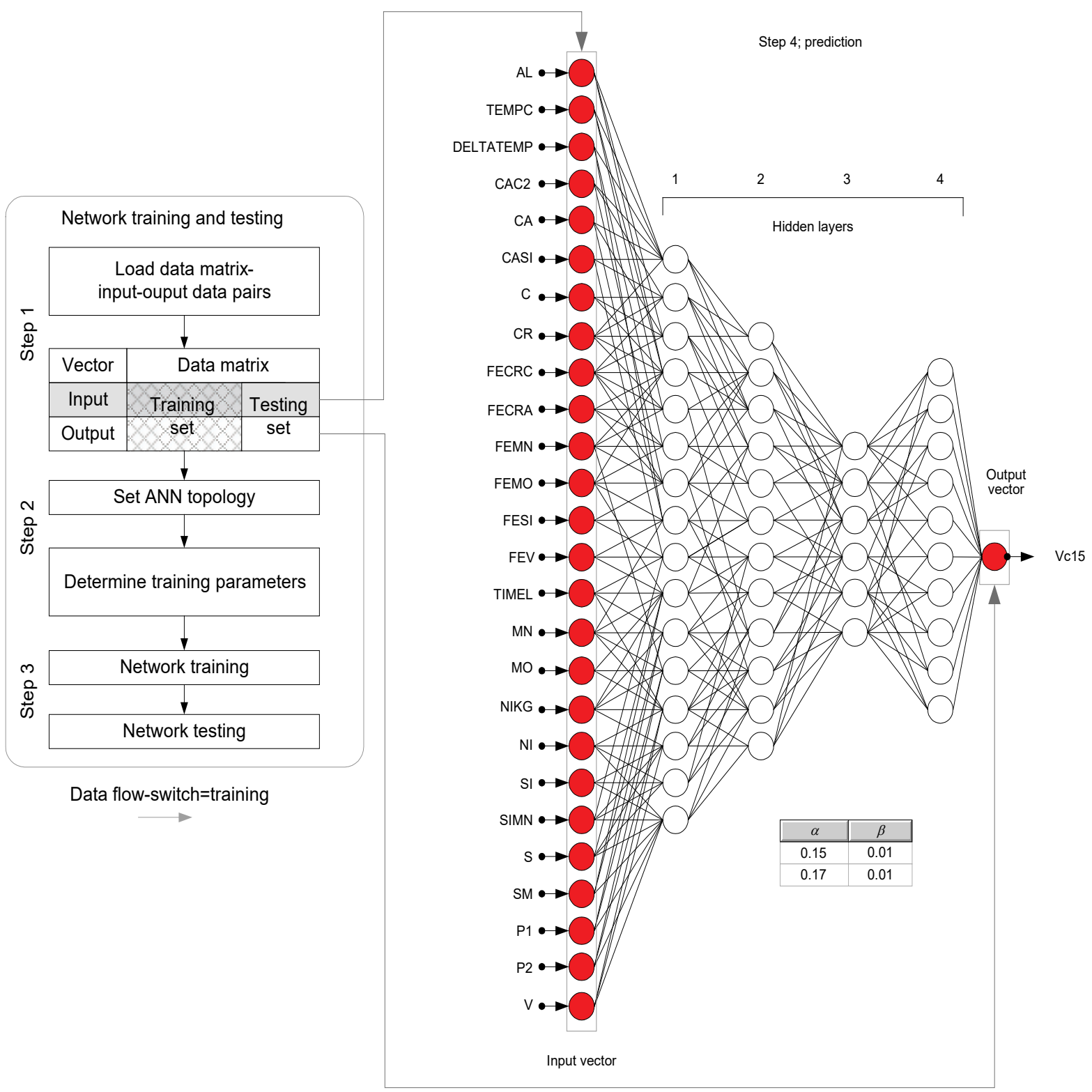

Figure 5 Flow chart for training and employing the ANN- based cutting speed model with its detail structure

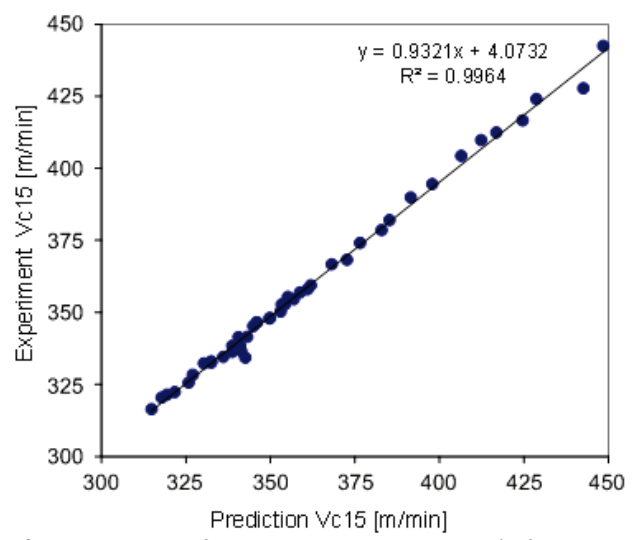

Figure 6 Scatter diagram of predicted and calculated Vc15 for testing data set
After training, the model is made and ready for prediction. The model is then verified with additional inputoutput data pairs that were not included in the training process. The output vector values were not delivered to the model, so the ANN had to predict them itself. Finally, the predicted values were compared with the actual cutting speeds and the prediction errors were calculated. Finally, in the fourth step, the trained ANN is used to predict the cutting speeds.

Fig. 5 shows a basic flow diagram for training ANN and for predicting cutting speeds via ANN. 


\section{OPTIMISATION OF THE 20MnV6 STEEL MAKING PROCESS USING PREDICTIVE ANALYTICS}

From 2018 to March 2020, 58 batches of 20MnV6 steel grade out of a total of 255 were produced. For this grade of steel, $39.8 \%$ of batches with inadequate machinability were detected. In 25 baches out of the 58 batches, the desired machinability was not achieved. The actual cutting speed, which enables tool life of 15 minutes, was lower than the reference cutting speed calculated according to ISO3685:1993. In process optimization, the performance machinability function according to ISO-3685:1993 is used. ANN was used to predict the maximum cutting speed with a tool life of 15 minutes. A $5.21 \%$ discrepancy was found between the experimentally obtained data and the results of the neural model. Fig. 7 shows the effects of process parameters on the maximum cutting speed $\mathrm{Vc} 15$ at which the cutting tool has a tool life of 15 minutes. Influences are determined using a neural network prediction model based on separate variation of individual parameter (the others are fixed) within the allowable parameter range.

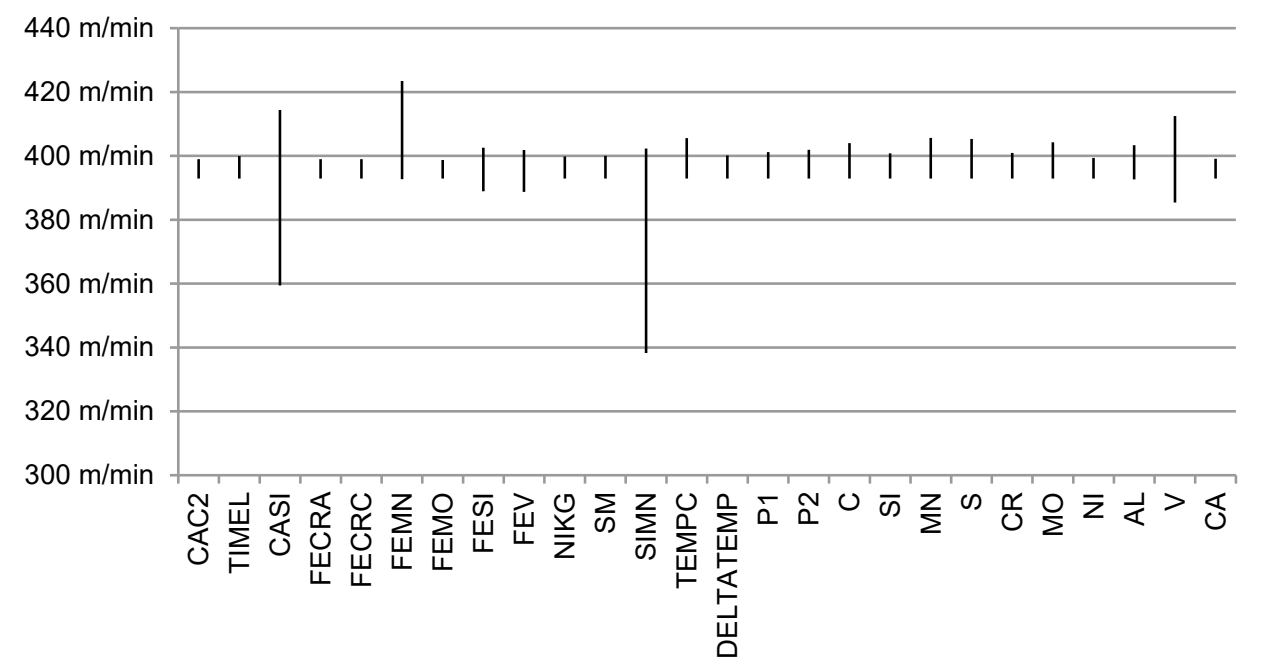

Figure 7 Influences of individual process parameters on the maximum cutting speed with the corresponding tool life of 15 minutes

The results in Fig. 7 show that calcium silicon (CASI), ferromanganese (FEMN) and silicomanganese (SIMN) have the greatest impact on steel machinability. In 2020, based on the determined influences of process parameter, the following changes were made during ladle treatment of $20 \mathrm{MnV} 6$ steel. First, Pheromanganese and ferrosilicon were partially replaced by silicon manganese. Second, the addition of sulfur wire has increased. Initially installed, secondary cooling nozzles were replaced with self-cleaning water nozzles due to frequent clogging.

The influence of other parameters that were not included in the process changes is explained below.

It follows from determining influences of vanadium content and ferrovanadium additives on machinability that at the required vanadium content in the melted material, ferrovanadium is added during ladle treatment according to the variable initial scrap vanadium content.

Water spraying during secondary cooling affects the temperature field of molten steel in the mold, which in turn affects the gradual solidification of melt, which forms a layered and chemically non-homogeneous cast structure.

Variation of the chemical composition within the technical delivery conditions does not affect the machinability of the steel.

Changes in steel production resulted in a statistically significant decrease of ferromanganese and ferrosilicon by $58.66 \%$ and $32.02 \%$, respectively, increased sulfur cored wire by $50.88 \%$, and a decrease of water pressure by 1.5 bar.
However, the analysis of cleanliness before and after the change of the steelmaking process showed that micro cleanliness did not change significantly.

For 24 batches of $20 \mathrm{MnV} 6$ steel produced in 2020, the achieved machinability was adequate, which confirmed the developed neural network model results. There was a $2.91 \%$ discrepancy between the experimentally obtained data and the results of the neural model.

\section{CONCLUSION}

Data for the development of the machinability model were obtained from two years of serial production of 26 steel grades from 255 batches and include seven parameters from secondary metallurgy, four parameters from the casting process, and content of ten chemical elements. The machinability was determined based on ISO 3685 .

The maximum cutting speed at which the cutting tool has a tool life of 15 minutes was calculated from the existing tool life-cutting speed curves for a particular steel grade and the actual experimentally determined tool life for an individual batch of steel.

The calculated cutting speeds together with the influential variables from the production process, were then used to train the ANN model.

The artificial neural network was used to predict the maximum cutting speed with a tool life of 15 minutes. A $5.21 \%$ discrepancy was found between the experimentally 
obtained data and the results of the neural model. Predictive analytics is then used to optimise the steel making process of one of the most problematic batches with inconsistent machinability of the otherwise most produced 20MnV6 steel grade. From 2018 to March 2020, 58 batches of 20MnV6 steel grade were produced out of a total of 255 produced batches of steel. For this grade of steel, $40.35 \%$ of batches with inadequate machinability were detected. In 24 of the 58 batches, the desired machinability was not achieved. Therefore, the actual cutting speed, which enables tool life of 15 minutes, was lower than the reference cutting speed calculated according to ISO-3685:1993.

In 2020, based on the results of the prediction model, the following changes were made during ladle treatment of 20MnV6 steel:

- Pheromanganese and ferrosilicon were partially replaced by silicon manganese

- The addition of sulfur wire has increased.

- Initially installed, secondary cooling nozzles were replaced with self-cleaning water nozzles due to frequent clogging.

Changes in steel production resulted in a statistically significant decrease of ferromanganese and ferrosilicon by $56.68 \%$ and $31.77 \%$, respectively, an increase in a sulfur cored wire by $51.41 \%$ and a decrease of water pressure by 1.5 bar. However, micro cleanliness did not change statistically significantly. The achieved machinability was adequate for all 24 batches of $20 \mathrm{MnV} 6$ steel produced in 2020 , which confirmed the developed neural network model results. However, there was a $2.91 \%$ discrepancy between the experimentally obtained data and the results of the neural model. The goal of further research is to use a predictive model to optimise other grades of steels with an emphasis on reducing micro cleanliness and additional agents while ensuring the desired machinability.

\section{Acknowledgements}

This research was funded by the Slovenian Research Agency; grant number ARRS P2-0162.

\section{Notice}

The paper was presented at MOTSP $2021-12^{\text {th }}$ International Conference Management of Technology - Step to Sustainable Production, which took place in Poreč/Porenzo, Istria (Croatia), on September 8-10, 2021. The paper will not be published anywhere else.

\section{REFERENCES}

[1] Stephenson, D. A. \& Agapiou, J. S. (1997). Metal Cutting Theory and Practice Manufacturing.

[2] Leskovar, P. \& Grum, J. (1986). The metallurgical aspects of machining. CIRP Annals, 35(2), 537-550. https://doi.org/10.1016/S0007-8506(07)60199-2

[3] Davim, J. P. (Ed.). (2008). Machining: fundamentals and recent advances. Springer Science \& Business Media.
[4] Desaigues, J. E., Lescalier, C., Arzur, A. B., \& Bomont, O. (2013, September). High Strength Steel solutions for automotive parts: State of the art of machinability enhancement and further developments. The Tenth International Conference on High Speed Machining, Technische Universität Darmstadt, 270-277.

[5] Kovach, C. W. \& Moskowitz, A. (1969). Effects of manganese and sulfur on the machinability of martensitic stainless steels. Trans Met Soc Aime, 245(10), 2157-2164.

[6] Ånmark, N., Karasev, A., \& Jönsson, P. G. (2015). The effect of different non-metallic inclusions on the machinability of steels. Materials, 8(2), 751-783. https://doi.org/10.3390/ma8020751

[7] Sathyamurthy, P., Vetrivelmurugan, R., \& Sooryaprakash, J. (2018, February). Improving the machinability of leaded free cutting steel through process optimisation. The IOP Conference Series: Materials Science and Engineering, 314(1), p. 012019. https://doi.org/10.1088/1757-899X/314/1/012019

[8] Vasconcellos da Costa e Silva, A. L. (2019). The effects of nonmetallic inclusions on properties relevant to the performance of steel in structural and mechanical applications. Journal of Materials Research and Technology, 8(2), 2408-2422. https://doi.org/10.1016/j.jmrt.2019.01.009

[9] ISO. (1993). ISO 3685:1993 Tool-life testing with single-point turning tools.

\section{Authors' contacts:}

Miha Kovačič, Assoc. Prof. (Corresponding author) STORE STEEL, d.0.0., Štore

Železarska cesta 3, 3220 Štore, Slovenija University of Ljubljana, Faculty of Mechanical Engineering,

Aškerčeva cesta 6, 1000 Ljubljana, Slovenija College of Industrial Engineering Celje, Celje Mariborska cesta 2, 3000 Celje, Slovenija +386 (0)3 7805 262, miha.kovacic@store-steel.si

\section{Shpetim Salihu, PhD student} University of Maribor, Faculty of Mechanical Engineering, Smetanova ulica 17, 2000 Maribor, Slovenia +38622207621, shpetim.salihu@student.um.si

Uroš Župerl, Assoc. Prof.

University of Maribor, Faculty of Mechanical Engineering, Smetanova ulica 17, 2000 Maribor, Slovenia +38622207621, uros.zuper@@um.si 